\title{
Article
}

\section{Aggregatibacter actinomycetemcomitans and Aggregatibacter aphrophilus in a Kenyan Maasai Adolescent Population and Inhibition of Leukotoxic Activity by Herbal Plants Used as Part of Oral Hygiene Procedures}

\author{
Mark Lindholm ${ }^{1}$, Rolf Claesson ${ }^{1}$, Arthur Kemoli ${ }^{2}{ }^{(D)}$, Tonnie Mulli ${ }^{3}$, Jan Oscarsson ${ }^{1}$, Dorte Haubek ${ }^{4}$ D \\ and Anders Johansson 1,*(D) \\ 1 Department of Odontology, Umeå University, 90187 Umeå, Sweden; mark.lindholm@umu.se (M.L.); \\ rolf.claesson@umu.se (R.C.); jan.oscarsson@umu.se (J.O.) \\ 2 Department of Paediatric Dentistry \& Orthodontics, University of Nairobi, Nairobi 00100, Kenya; \\ musakulu@gmail.com \\ 3 Department of Periodontology, University of Nairobi, Nairobi 00100, Kenya; mullitonnie@yahoo.com \\ 4 Department of Dentistry and Oral Health, Health, Aarhus University, DK-8000 Aarhus, Denmark; \\ dorte.haubek@dent.au.dk \\ * Correspondence: anders.p.johansson@umu.se; Tel.: +46-70-2917707
}

check for updates

Citation: Lindholm, M.; Claesson, R.; Kemoli, A.; Mulli, T.; Oscarsson, J.; Haubek, D.; Johansson, A. Aggregatibacter actinomycetemcomitans and Aggregatibacter aphrophilus in a Kenyan Maasai Adolescent Population and Inhibition of Leukotoxic Activity by Herbal Plants Used as Part of Oral Hygiene Procedures. J. Clin. Med. 2021, 10, 5402. https://doi.org/10.3390/ jcm10225402

Academic Editor: Izumi Asahina

Received: 7 October 2021

Accepted: 17 November 2021

Published: 19 November 2021

Publisher's Note: MDPI stays neutral with regard to jurisdictional claims in published maps and institutional affiliations.

Copyright: (c) 2021 by the authors. Licensee MDPI, Basel, Switzerland. This article is an open access article distributed under the terms and conditions of the Creative Commons Attribution (CC BY) license (https:/ / creativecommons.org/licenses/by/ $4.0 /)$.

\begin{abstract}
Background: A virulent genotype (JP2) of the periodonto-pathogen, Aggregatibacter actinomycetemcomitans $(A a)$, is widespread in North and West Africa, while its presence in East Africa has not been thoroughly investigated. This JP2 genotype is associated with periodontitis in adolescents and has a high leukotoxicity. The aim of the study was to examine the prevalence of $A a$ and its JP2 genotype, the prevalence of the oral, commensal Aggregatibacter aphrophilus in a Maasai adolescent population, and the effect of herbal plants for inhibition of leukotoxicity. Methods: A total of 284 adolescents from Maasai Mara, Kenya, underwent an oral examination and microbial sampling. The presence of $A a$ and $A$. aphrophilus was analyzed by quantitative PCR and cultivation (the 58 samples collected at the last day of field study). The collected $A a$ strains were characterized and leukotoxin promoter typed. Additionally, herbal plants commonly used for oral hygiene were assessed for the inhibition of leukotoxicity. Results and Conclusions: The prevalence of $A a$ in stimulated whole saliva was high (71.8\%), with the JP2 genotype detected in one individual, and A. aphrophilus in $99 \%$ of the sampled individuals. The commonly used herbal plant, Warburgia ugandensis, inactivated $A a$ leukotoxicity. The Aa virulence might be reduced through use of W. ugandensis and the high levels of A. aphrophilus.
\end{abstract}

Keywords: Aggregatibacter actinomycetemcomitans; Aggregatibacter aphrophilus; leukotoxicity; herbal plants; Maasai adolescents

\section{Introduction}

Aggregatibacter actinomycetemcomitans is a Gram-negative, facultative anaerobic bacterium frequently found in the oral cavity [1]. Although the bacterium has been shown to be strongly associated with periodontitis in adolescents, it can also exist in the oral cavity without causing disease [1,2]. Moreover, occasionally, this species is also associated with cases of extraoral diseases, such as endocarditis and rheumatoid arthritis [3,4]. The leukotoxin produced by the bacterium has recently been shown to be associated with rheumatoid arthritis [4]. Earlier studies on the association between periodontitis and A. actinomycetemcomitans have shown that the JP2 genotype, which has the ability to produce high amounts of leukotoxin, has a very strong association with periodontitis [5,6]. A typical characteristic of the JP2 genotype is a 530-basepair [bp] deletion in the promoter of the ltxCABD operon, encoding the leukotoxin [7]. The leukotoxin expressed by A. actinomycetemcomitans has been 
shown to not only kill leukocytes, but also to activate neutrophil degranulation, to protect the bacterium from phagocytic killing, and to initiate pro-inflammatory death of human macrophages [8-10]. These properties of the leukotoxin are associated with the cellular and molecular mechanisms involved in the pathogenicity of periodontitis [11]. Whereas periodontitis associated with $A$. actinomycetemcomitans, especially in adolescents, has been studied in northern and western parts of Africa, not much is known about the presence of A. actinomycetemcomitans in eastern parts of Africa [12]. Some studies performed in Sudan have indicated a rather high degree of rapidly progressing forms of periodontitis $[13,14]$ associated with $A$. actinomycetemcomitans in the Sudanese population. However, no JP2 genotype of $A$. actinomycetemcomitans was identified [14]. Another Sudanese study discovered the JP2 genotype in one patient, who exhibited periodontitis with rapid progress [15], but the overall results from these examinations supported the notion that the presence of the JP2 genotype in East Africa is rather low [12]. Interestingly, an A. actinomycetemcomitans isolate sampled from a patient of Ethiopian origin living in Sweden was found to have an atypical 640-bp deletion in the leukotoxin gene promoter [16]. Whether this genotype might have originated from East Africa is not known. To the best of our knowledge, only one investigation on the topic was published about 30 years ago, which assessed the prevalence of periodontitis in adolescents in Kenya and reported a low prevalence of the disease compared to the studies carried out in Sudan [13-15,17]. The lack of microbial analyses in that study prompted us to investigate the presence of periodontal pathogens and other factors that could influence the susceptibility to periodontitis in Kenyan adolescents. The studied population in the present work consisted of adolescents living in Maasai Mara North Conservancy, Kenya, and has been described earlier [18].

Previous studies, which examined the presence of $A$. actinomycetemcomitans in relation to the occurrence of periodontal attachment loss, have included analyses of subgingival plaque samples $[2,19]$. However, a recent study examined the salivary presence of the JP2 genotype of A. actinomycetemcomitans in Moroccan adolescents positive for the JP2 genotype that has previously been detected in the subgingival plaque $[19,20]$. The JP2 genotype of A. actinomycetemcomitans could also be detected in saliva from all the 22 participants in the study, with the highest levels of the JP2 genotype in individuals with attachment loss $(\geq 3 \mathrm{~mm})$. This indicates that saliva is a suitable source to use for the examination of the presence of $A$. actinomycetemcomitans and its JP2 genotype on an individual basis.

Plants and natural products are widely used globally as substitutes for toothbrushes due to the cost, availability, customs, and religious reasons. Many of the plants used for oral hygiene purposes in Africa as well as other parts of the world have been shown to have antimicrobial properties against oral bacteria, including periodontal pathogens $[20,21]$. Among plants, Psidium guajava has been efficient in neutralizing the activity of the A. actinomycetemcomitans leukotoxin [22]. The most common herbal plants used by the population living in Maasai Mara, Kenya, have recently been reviewed [23]. In Maasai Mara, the use of plants for oral hygiene is common and includes a variety of different species [24], but the effects of these plants on the oral microbiota in this population has, however, not been studied intensely. In some urban and rural areas of the world, there is limited or no access to dental care and related products. It is therefore of particular importance to identify appropriate tools easily available for use in these populations.

Aggregatibacter aphrophilus is closely related to A. actinomycetemcomitans, when comparing the gene content. While $A$. aphrophilus as well as A. actinomycetemcomitans can be found in cases of endocarditis, it is not associated with periodontitis [25]. Considering that there is a large genetic similarity between these two bacterial species, it cannot be excluded that they compete with each other to proliferate in the same ecological niche in the oral cavity [3].

The primary aim of the present study was to examine the salivary presence, levels, and genotypic/phenotypic characteristics of A. actinomycetemcomitans and A. aphrophilus in a population $(n=284)$ of students at primary and secondary schools in the Maasai Mara area of Kenya. The secondary aim was to assess local factors that may potentially reduce 
the virulence of $A$. actinomycetemcomitans, such as anti-leukotoxic effects from herbal plants used for oral hygiene.

\section{Materials and Methods}

\subsection{Study Population}

The study population consisted of 284 school children, aged 14 to 18 years (mean age: 15.0; SD 1.1; range 14-18 years), from five schools located in the Mara North Conservancy, Narok County, Kenya. The study population has previously been described in detail [18]. A schematic overview of the present study is shown in Figure 1.

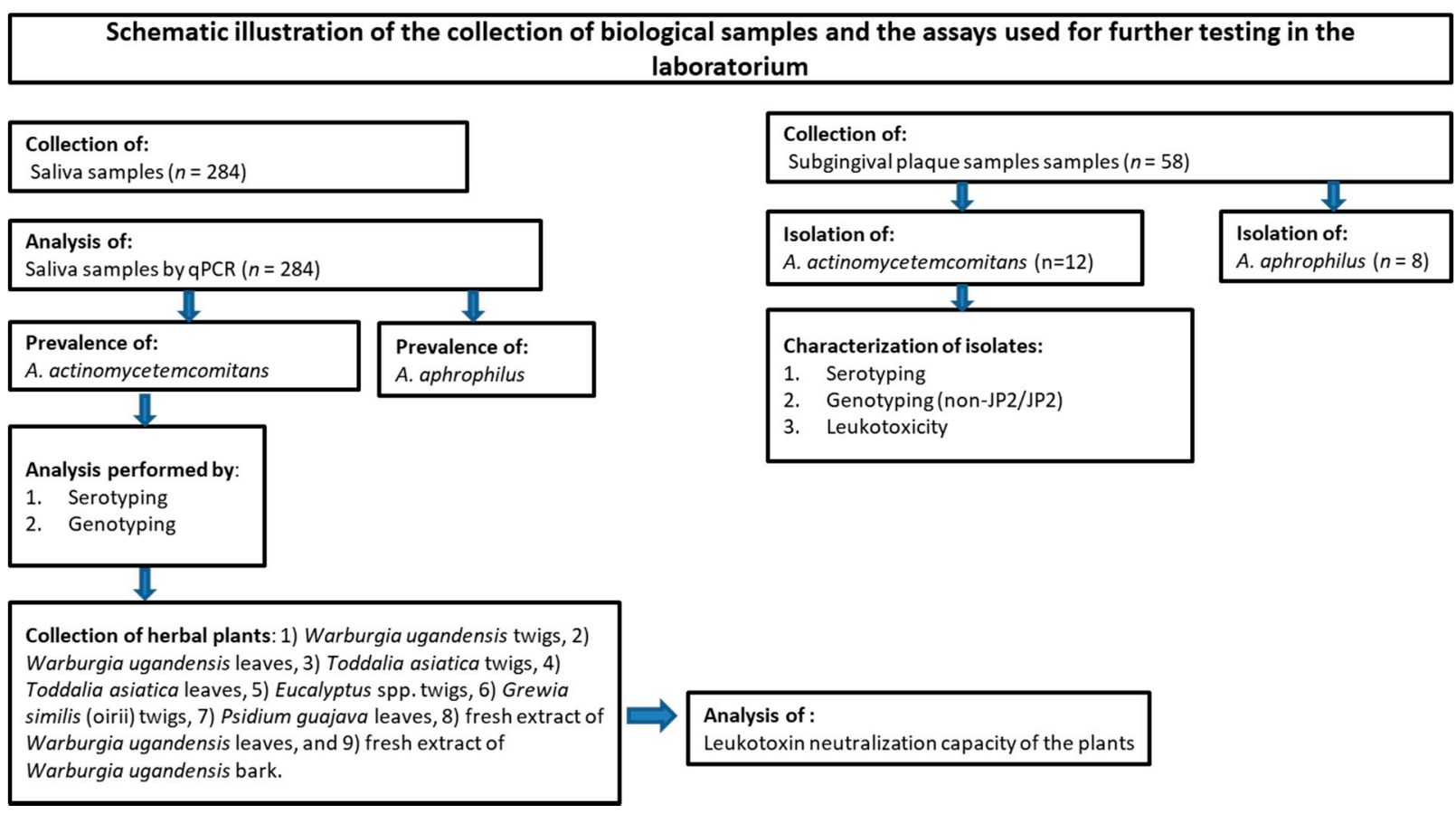

Figure 1. Flowchart describing the outline of the present work, assessing an adolescent population in Mara North Conservancy, Kenya $(n=284)$.

\subsection{Description of Field Conditions for Biological Sampling}

Oral examinations were executed under field conditions in an ordinary classroom at the respective schools of the children in the Mara North Conservancy during five full working days. Subjects were made to lie on top of a table, facing a natural light source. A supplementary light source, a headlamp, was used to augment the natural light during the examination of the oral cavity. Using clean disposable mouth mirrors and tweezers, an oral examination was carried out to detect the status of the dentition. The methods and data from the clinical examination, as well as the field conditions, have been described previously; however, none of the clinical data are reported on in the present study $[12,18]$.

\subsection{Sampling of Stimulated Whole Saliva}

The participants $(n=284)$ were asked to chew on a piece of paraffin wax for one minute, and the stimulated whole saliva was thereafter collected in a disposable plastic cup. One $\mathrm{ml}$ of the saliva was mixed with an equal volume of Saliva DNA Preservation Buffer (2X) (Norgen Biotek Corporation, Thorold, ON, Canada) in a $2 \mathrm{~mL}$ sterile tube and stored at room temperature until the DNA was isolated. This procedure was done prior to the oral examination made for other purposes [18]. 


\subsection{Sampling of Subgingival Plaque for Microbial Cultivation}

From a subgroup of the study population ( $n=58$; participants included on the last day of the field study at schools), dental plaque was collected with sterile paper points and inserted subgingivally in four periodontal pockets (mesial periodontal pockets on the 4 first permanent molars) for 10-20 s. The paper points from each patient were pooled into a tube with $2 \mathrm{~mL}$ of VMGAIII [26] transport medium supplemented with Nystatin (2 mg/L).

\subsection{Isolation of DNA from Stimulated Whole Saliva}

Five hundred $\mu \mathrm{L}$ saliva in buffer was mixed with $500 \mu \mathrm{L} 10 \mathrm{mM}$ Tris buffer with $1 \mathrm{mM}$ EDTA $(\mathrm{pH}=8.0)$ in a $1.5 \mathrm{~mL}$ Eppendorf tube and placed in an extraction instrument (Diasorin, Dublin, Ireland). DNA was extracted from $550 \mu \mathrm{L}$ of the sample mixture with the Viral DNA extraction kit (Diasorin, Dublin, Ireland) with an elution volume of $100 \mu \mathrm{L}$ in accordance with the protocol of the manufacturer. The samples were stored at $+4{ }^{\circ} \mathrm{C}$ until the analyses were performed.

\subsection{Quantification of A. actinomycetemcomitans and A. aphrophilus by $q P C R$}

The loads of A. actinomycetemcomitans in the samples were quantified by qPCR using a Corbett Research Rotor Gene ${ }^{\mathrm{TM}} 6000$ Real-Time PCR Thermocycler (Qiagen, Valencia, CA, USA). Specific primers and PCR cycling conditions used were as previously described [27]. The qPCR mixtures $(10 \mu \mathrm{L})$ for the quantification of A. actinomycetemcomitans contained $5 \mu \mathrm{L}$ Kapa Sybr Green (KK 4601) (Kapa Biosystems, Boston, MA, USA), $4 \mu \mathrm{L}$ template, and $1 \mu \mathrm{L}$ of the specific primer mix $(0.5 \mu \mathrm{mol} / \mathrm{L}$ each). Each run included three negative samples $\left(\mathrm{H}_{2} \mathrm{O}\right)$ and standard mixtures with a given concentration equivalent to $10^{1} ; 10^{2}, 10^{3}, 10^{4}$, $10^{5}, 10^{6}, 10^{7}$, and $10^{8}$ A. actinomycetemcomitans cells $/ \mathrm{mL}$ were prepared as described for the samples. The detection limit for the bacterium was set to $100 / \mathrm{mL}$. A. aphrophilus loads in the samples were determined using the same general set up, however, using $3 \mu \mathrm{L}$ template and $2 \mu \mathrm{L}$ of the specific primer mix $(0.5 \mu \mathrm{mol} / \mathrm{L}$ each $)$ in the qPCR reactions, and with each run including one negative sample $\left(\mathrm{H}_{2} \mathrm{O}\right)$. The oligonucleotide primers used were a forward (5'-CCTACACCAGCGTTTATTTC- $\left.3^{\prime}\right)$ and a reverse (5'-CTGAGGTTTACGCCAGTC-3') primer, targeting an $A$. aphrophilus-specific gene sequence, encoding a putative hemolysin co-regulated protein (ACS98147; CP001607; [28]).

\subsection{Sero- and Genotyping of A. actinomycetemcomitans in Stimulated Whole Saliva Samples}

Samples containing $\geq 10^{4}$ A. actinomycetemcomitans cells $/ \mathrm{mL}$ were analyzed with primers specific for serotype $\mathrm{b}$ of A. actinomycetemcomitans according to a previously described method [29]. Serotype b-containing samples were further analyzed for the presence of the JP2 genotype of A. actinomycetemcomitans by using leukotoxin promoter-specific oligonucleotide primers, as described previously [30]. PCR amplicons corresponding to the size (bp) of the JP2 genotype were isolated from agarose gels and their DNA sequences determined as described previously [16].

\subsection{Detection of A. actinomycetemcomitans and A. aphrophilus in Plaque Samples by Cultivation}

For the detection of $A$. actinomycetemcomitans in the dental plaque samples $(n=58)$ collected for cultivation from periodontal pockets of permanent first molars, aliquots $(100 \mu \mathrm{L})$ were spread on a species-specific agar medium described by Slots, with the exception that the serum was omitted [31]. For the inhibition of growth of contaminating bacteria, i.e., enterobacteria, the samples were also spread on a medium modified as described by Höglund Åberg et al. [32]. The plates were incubated at $37^{\circ} \mathrm{C}$ in aerobic atmosphere containing $5 \% \mathrm{CO}_{2}$ for 3-5 days. Isolates from all A. actinomycetemcomitanspositive subjects $(n=12)$ were collected. The A. actinomycetemcomitans JP2 genotype reference strain, named HK1651, was included for comparison [33]. As reference, using the same approach, a smaller collection of $A$. aphrophilus strains $(n=8)$ were isolated from selected subjects. These isolates are referred to as 4-Aap-K, 12-Aap-K, 13-Aap-K, 21-Aap-K, 
29-Aap-K, 30-Aap-K, 32-Aap-K, and 53-Aap-K, and have been found to exhibit resistance to human serum at a level similar to A. actinomycetemcomitans strains [34].

\subsection{Characterization of $A$. actinomycetemcomitans Isolates}

For serotyping, suspensions of the isolates were taken through a shaking block-heater at $95{ }^{\circ} \mathrm{C}$ for eight minutes and centrifuged. The supernatants obtained were used as a template and a PCR-based method described by Höglund Åberg et al. [32] was used. For the determination of the leukotoxicity, the isolates were cultured on peptone yeast extract agar at $37{ }^{\circ} \mathrm{C}$ in aerobic atmosphere containing $5 \% \mathrm{CO}_{2}$ for $48 \mathrm{~h}$, and the bacteria were harvested into $300 \mathrm{mM} \mathrm{NaCl}$ in phosphate buffered saline (PBS). The density was adjusted to $\mathrm{OD} 600 \mathrm{~nm}=10\left(\approx 10^{10}\right.$ cells $\left./ \mathrm{mL}\right)$, and the mixture was agitated at $4{ }^{\circ} \mathrm{C}$ for $60 \mathrm{~min}$. The cells were pelleted by centrifugation $\left(10,000 \times g\right.$ for $10 \mathrm{~min}$ at $\left.4^{\circ} \mathrm{C}\right)$. The cell-free supernatant (5\%) was added to cultures of phorbol 12-myristate 13-acetate (PMA)-differentiated THP-1 cells for $120 \mathrm{~min}$, and cell lysis was determined by quantification of the leakage of LDH from damaged cells [35]. The release of LDH was expressed as \% of the maximal release $(100 \%)$ caused by incubation with $0.1 \%$ Triton $x-100$.

\subsection{Collection and Extraction of Herbal Plants}

Material from six different plants was collected in the Maasai Mara region of Kenya in collaboration with local experts. Plant species collected were (1) W. ugandensis twigs, (2) W. ugandensis leaves, (3) Toddalia asiatica twigs, (4) T. asiatica leaves, (5) Eucalyptus spp. twigs, (6) Grewia similis (oirii) twigs, (7) Psidium guajava leaves, (8) fresh extracts of $W$. ugandensis leaves, and (9) fresh extract of W. ugandensis bark. The P. guajava were not used in Maasai Mara but was included as a positive control based on previous findings [22]. The plant material was disintegrated and mixed with $70 \% \mathrm{EtOH}(250 \mathrm{mg} / \mathrm{mL})$ and agitated at room temperature for $24 \mathrm{~h}$. The insoluble material was removed by centrifugation $(5000 \times g$ for $20 \mathrm{~min}$ ), and the supernatants were analyzed in leukotoxin neutralization assays.

\subsection{Determination of the Leukotoxin Neutralization Capacity of Herbal Plants}

The supernatants (1\%) were added to cultures of PMA-differentiated THP-1 cells in the presence of leukotoxin $(200 \mathrm{ng} / \mathrm{mL})$ for $120 \mathrm{~min}$, and cell lysis was determined by quantification of the leakage of lactate dehydrogenase (LDH) [36]. Purified leukotoxin was obtained by gel filtration of surface extracts from NaCl-treated cultures of JP2 genotype $A$. actinomycetemcomitans cells as described previously [9]. The release of LDH was expressed as percentage (\%) of the maximal release (100\%) caused by incubation with $0.1 \%$ Triton $x-100$. The ability of each extract to inhibit leukotoxicity was registered as a decrease in leukotoxin-induced cell lysis.

\subsection{Statistical Analyses}

A one-tailed paired $t$-test with Excel (Microsoft, Redmond, WA, USA) was used to determine any significant differences between samples. The confidence interval was set at $95 \%$ ( $p$-value 0.05$)$.

\section{Results}

3.1. Presence of A. actinomycetemcomitans and A. aphrophilus in Saliva Samples Determined by $q P C R$

The prevalence of $A$. actinomycetemcomitans in the collected 284 stimulated whole saliva samples was $71.8 \%$, with 204 out of the 284 analyzed saliva samples containing $\geq 100$ cells of this species per $\mathrm{mL}$. The distribution of the bacterium in specific concentration groups is shown in Figure 2. The prevalence of $A$. aphrophilus was higher, and in the 284 analyzed saliva samples, $99 \%(n=282)$ contained $\geq 100$ cells of this organism per $\mathrm{mL}$. The distribution of the bacterium in specific concentration groups illustrates the generally higher loads of $A$. aphrophilus in the saliva samples relative to the levels of A. actinomycetemcomitans (Figure 2). This difference was emphasized by plotting the concentrations of A. aphrophilus 
against the concentrations of A. actinomycetemcomitans in the respective samples, revealing clearly higher levels of the former organism (Figure 3 ). In a few outliers $(n=2)$, however, we observed that there were instead high levels of A. actinomycetemcomitans relative to A. aphrophilus.

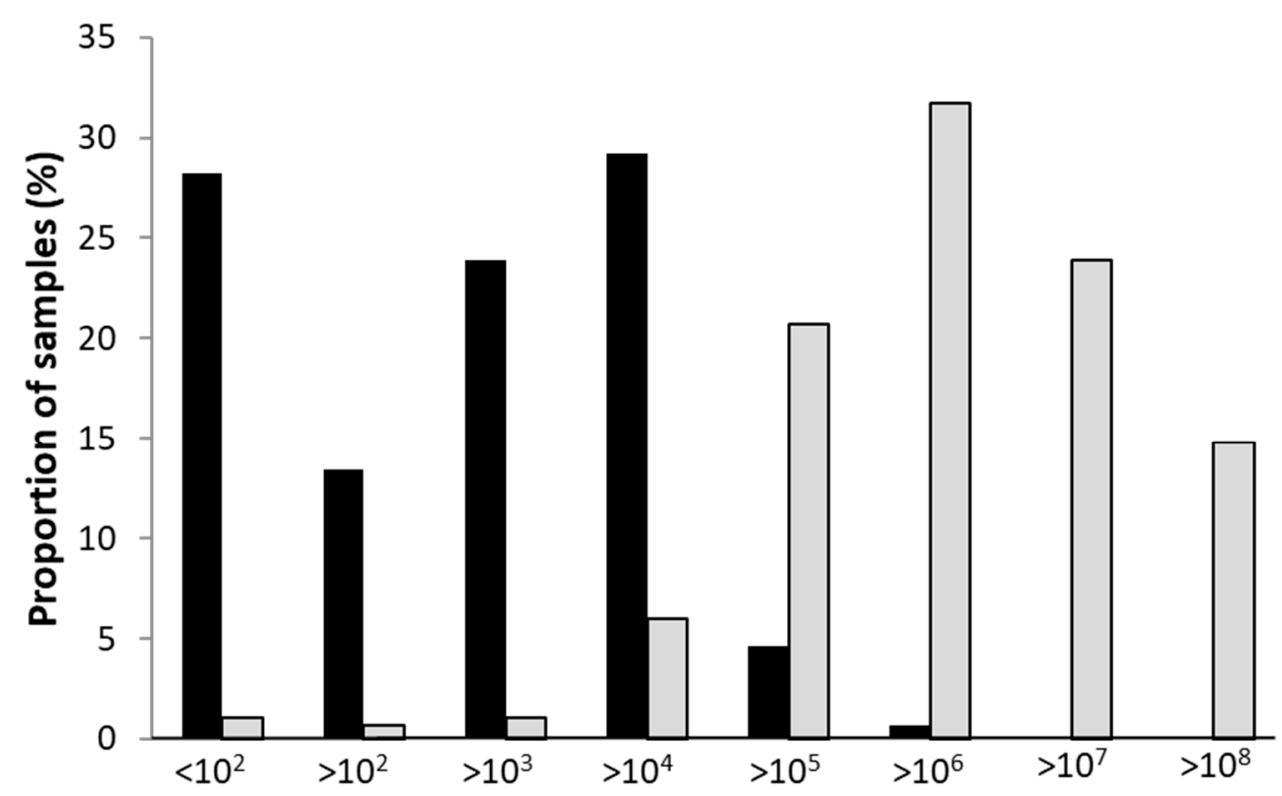

A. actinomycetemcomitans or A. aphrophilus $\mathrm{cfu} / \mathrm{mL}$

Figure 2. Proportions of saliva samples with indicated concentrations (cfu/mL) of A. actinomycetemcomitans (black bars) and A. aphrophilus (gray bars), respectively, as determined by qPCR. Samples from a total of 284 individuals of the Maasai Mara adolescent population were analyzed.

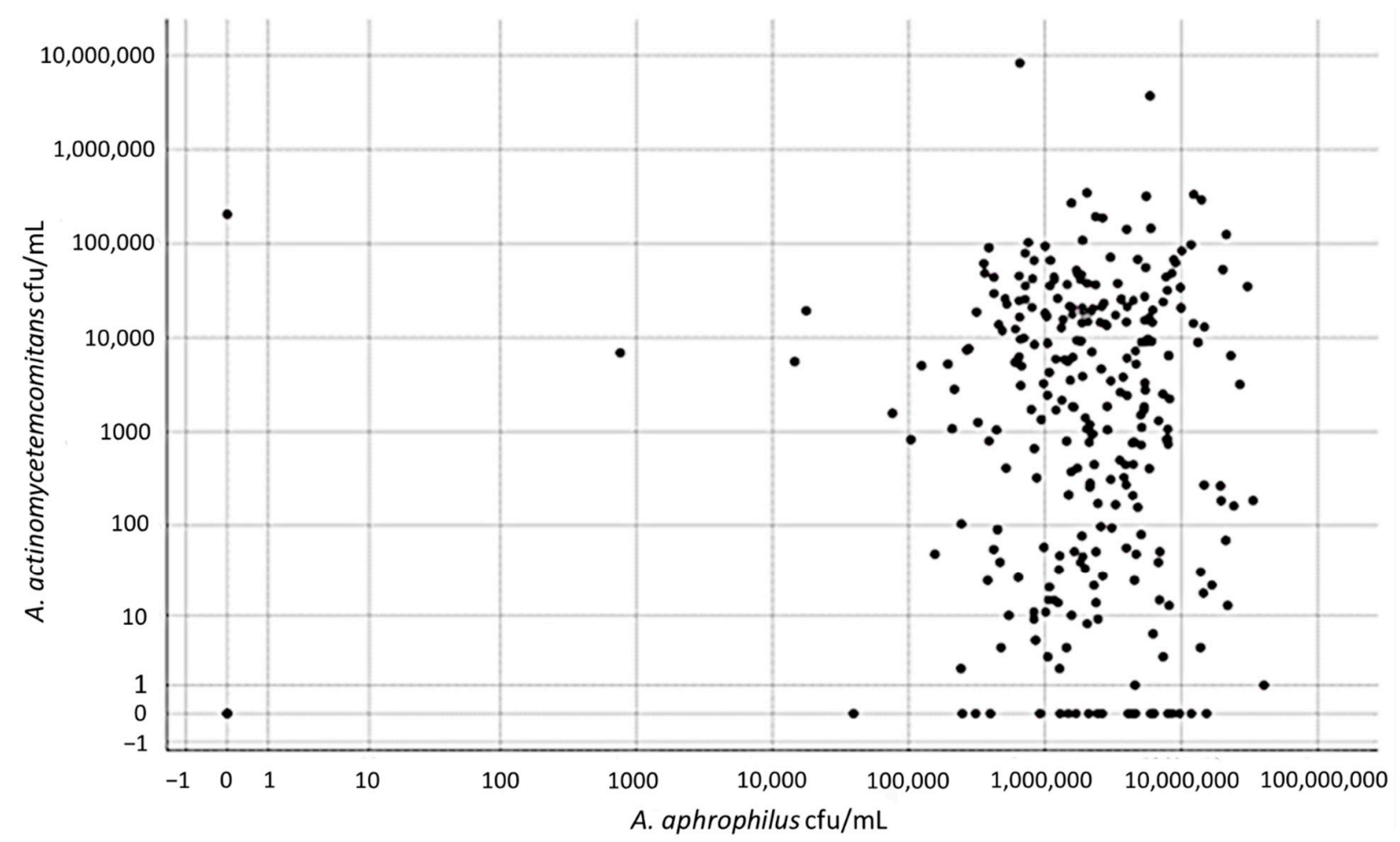

Figure 3. A comparison of the levels $(\mathrm{cfu} / \mathrm{mL})$ in saliva of A. actinomycetemcomitans and A. aphrophilus, respectively, as determined by qPCR. Samples from a total of 284 individuals of the Maasai Mara adolescent population were analyzed. 


\subsection{Sero- and Genotyping of A. actinomycetemcomitans in Stimulated Whole Saliva Samples}

When the 98 samples $(34.5 \%)$ containing $\geq 10^{4}$ A. actinomycetemcomitans cells $/ \mathrm{mL}$ were studied with regard to serotype $b$ strains, 15 samples $(16.5 \%)$ were found to contain this serotype. Saliva samples with $<10^{4}$ A. actinomycetemcomitans cells $/ \mathrm{mL}$ could not be serotyped with a reliable result. The subsequent leukotoxin promoter typing showed that 1 of the 15 samples had the 530-bp deletion, which is a characteristic of the JP2 genotype of A. actinomycetemcomitans (Figure 4).

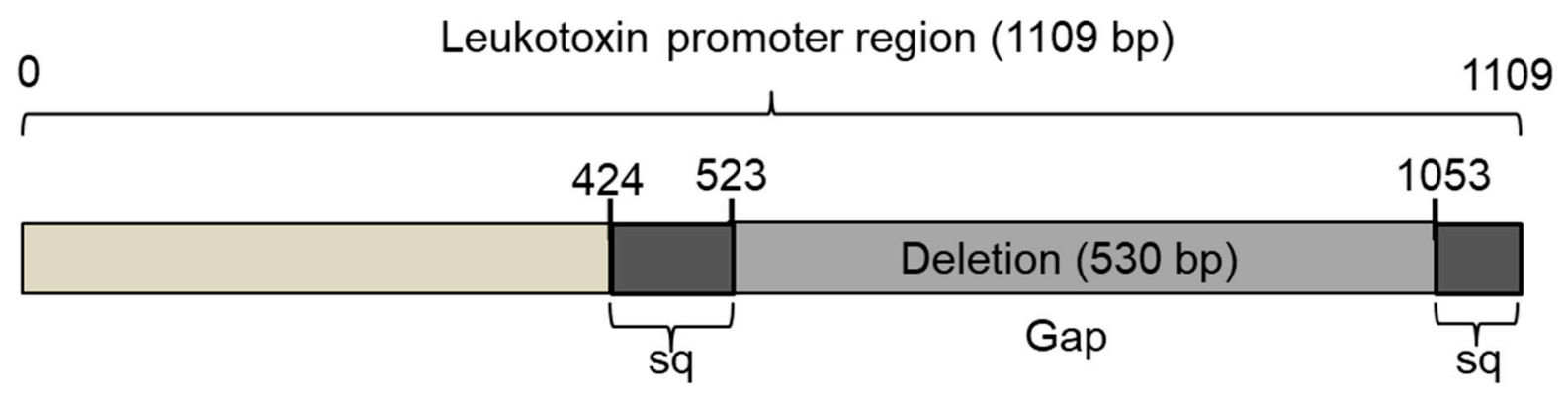

\section{Leukotoxin promoter region sequence}

IIT TAA TCA AAT GAA AAA AAA CAA AGC GGT AAT GAA AAT TGC CGC ПTा TाC ПाT TाG AGA AAT ATG ACA GTC AAA ATC TTA CAG ATC AAA ACC TGA TAA CAG TAT TाT CTC AGT CTA ATT TIT GCG TAT TAA TAC AAT ACG GGA TTG CGT AGA TAA AGT ATT ATC AAA AAA CTA ATA ATT TTA TGA AAT TAA ATA ATT TाT TCT ATT GAC TAT TAA AGA ATC CGG AGT AAA TTA GTC TCC AAA ATT AAC CAA AAC TAG GTA ATT TAT CCG GTC AAA GGT TAT CTT AAG TAT TAA CCC TAA GAA AAA GGA AAA CGA GTA TGT CCA GTA CAG AAT ATG CTC CAT TाT ATC TCC GTT TTA TTC AGT TCC CAA GTA ATG AAG TIT TAC TCT ATG AAT ACT GGA AAC TTG TTC AGA ATT TTG TAC AAA AGG TTA GTA AAA TAA CGG TAA GAT TAG CAC AAA TCG TTG GCA TTC TCG GCG AAA AAA CTA TIT GGA AAT ACC AAA GTA CTT TTA ATG ATG GCA TGC TGG AAG GTG AGG TAG CTA AAC AAG AAG TIT CCC TCA CTT TAA GAA ATA GTG CTT TAC TTG TCG CAA GTG CCA TAG TTA TCC ACT TTA AAT CTA ATT TTA CCA ACC TTC TTA TAC TGT CAC AGA TTA CAC AAT ATT GTA GAC ATC GCC CTA AAT CTA AAA AAA GTA AAT ACT TCC CCC TCT ACC TCT CTT GCT TAT TAC GCA GAC GAT TAA CTG AAT TTA AAA TTA CCC TTC TAC CGT TGC CAT GGG GCT AGC TGC TAT ATA GCT ATG AAG ATC AAA TCC CGG TIT TCA TTG TAA ATT TAA AAA TAT ATA AGA AAT AAT CTG AAG CCG ACT TTA TIT TTA CCC AAC TAC GAA TCA CTC ATT TAA ATT AAG GTT TAT TAT GCA AAA TAA TAA AGC TTG AAT ATA TTC CTG TAA TAT AAG GTT AAA TAA GTT ATA TIT CTA TाT ATT GTT TAA CAA TAA TAA TTA AAT CAT AGT CTA TIT GAT TTC GTA ATG AGT TTG GCA TIT TCT GTC ATG CGT CGA TCG TGT ATA TTG TGG TIT GGT TAT CTT AAT CAA AAT AAA TTA TTA ACA AGG AGA TIT AAT

Figure 4. Schematic illustration of the leukotoxin promoter region. Extracted DNA from saliva of individuals positive for A. actinomycetemcomitans strains of serotype $\mathrm{b}$ was amplified by PCR using leukotoxin promoter-specific primers. The PCR products were visualized on an agarose gel, and one DNA band corresponding in size to that of the JP2 genotype was extracted from the gel and sent for DNA sequencing. The obtained sequence (highlighted in black) revealed the absence of the specific 530 base pair (bp) fragment (highlighted in dark gray), which is a specific characteristic of the JP2 genotype of A. actinomycetemcomitans.

3.3. Presence of A. actinomycetemcomitans in Subgingival Plaque Samples Determined by Cultivation

Samples from 58 individuals were cultured on agar plates, and A. actinomycetemcomitans could be isolated from 12 (22.1\%) of 53 cultivable samples. It was not possible to examine five plates of the total number of samples due to overgrowth of other microbes. total of 11 (92\%) of the 12 individuals, where A. actinomycetemcomitans could be detected by cultivation of the plaque sample, had $>3000$ bacterial cells $/ \mathrm{mL}$ of this species in the saliva sample. Serotyping showed the presence of three different serotypes, five serotype a $(41.7 \%)$, four c $(33.3 \%)$, and three $\mathrm{f}(25 \%)$ (Table 1$)$. Thus, no A. actinomycetemcomitans strains 
of the JP2 genotype of serotype $\mathrm{b}$ were identified by cultivation methods. A. aphrophilus was isolated from the plaque samples from eight individuals, who all carried a level of this species $>10^{2} / \mathrm{mL}$ in their corresponding saliva sample.

Table 1. Plaque samples for cultivation were collected from 58 of the students examined on the last day of the planned field study. Five samples were discarded due to overgrowth of bacteria and yeast. In 53 of the 58 plaque samples collected, A. actinomycetemcomitans could be detected and isolated in $12(22.6 \%)$ of them. These 12 isolates were serotyped and examined for their leukotoxic activity.

\begin{tabular}{ccc}
\hline Number & Aa Isolate & Serotype \\
\hline 1 & Aa-3-K & $\mathrm{f}$ \\
2 & Aa-4-K & $\mathrm{f}$ \\
3 & Aa-6-K & $\mathrm{c}$ \\
4 & Aa-11-K & $\mathrm{f}$ \\
5 & Aa-17-K & $\mathrm{c}$ \\
6 & Aa-23-K & $\mathrm{c}$ \\
7 & Aa-25-K & $\mathrm{a}$ \\
8 & Aa-29-K & $\mathrm{a}$ \\
10 & Aa-30-K & $\mathrm{c}$ \\
11 & Aa-38-K & $\mathrm{a}$ \\
\hline
\end{tabular}

\subsection{Characterization of Cultivated A. actinomycetemcomitans Isolates}

Leukotoxicity analyses of the A. actinomycetemcomitans isolates showed the presence of both low and intermediate leukotoxic phenotypes (Figure 5A). The isolate with the highest leukotoxicity (isolate 12; serotype a), as determined by the use of the LDH release assay (10), was compared with the JP2 genotype strain, HK1651, in a dose-response test. This indicated a substantial difference between the JP2 genotype and the selected isolate, which exhibited a lower leukotoxicity than the JP2 genotype (Figure 5B). However, none of the isolated A. actinomycetemcomitans strains were from serotype b or with the 530-bp leukotoxin promoter deletion.

\subsection{Effects of Herbal Plants on Leukotoxic Activity}

The ability of plant extract to inhibit leukotoxic activity was significant only for the extracts based on P. guajava leaves or fresh leaves or bark from W. ugandensis (Figure 6). It was shown by dose-response analyses that the neutralizing capacity of W. ugandensis bark extract was at a similar level as that of P. guajava leaves (Figure 7). Based on oral communications with examined pupils and their teachers, all individuals at the research site used W. ugandensis daily for oral cleaning. The pupils at the different schools could easily identify the tree from where they picked their chewing stick material (Figure 8). 

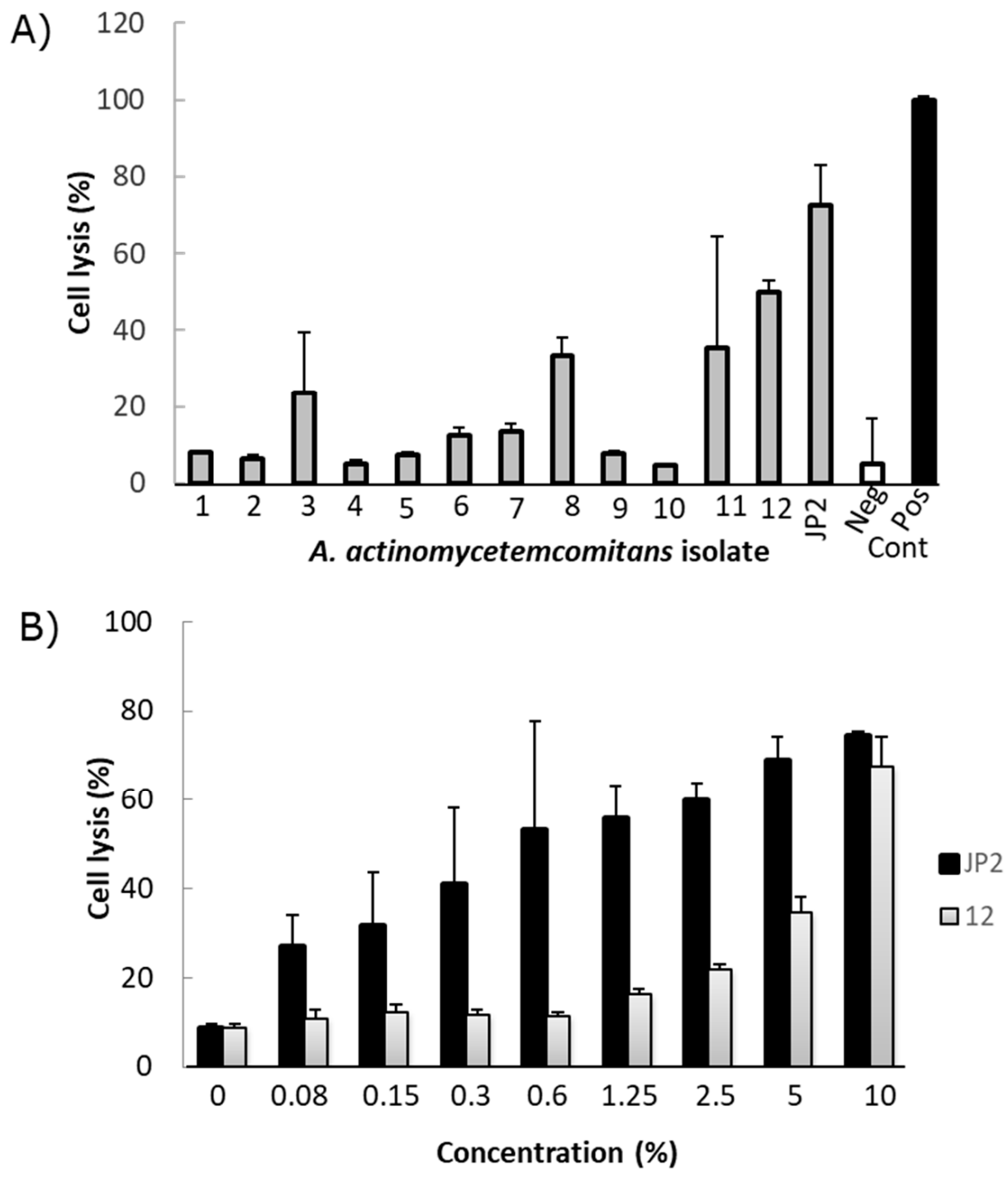

Figure 5. Leukotoxic activity of extracts from 12 different isolates of A. actinomycetemcomitans and a JP2 genotype strain of A. actinomycetemcomitans as comparison. (A) Effect on cell lysis in cultures of THP-1 cells exposed for $2 \mathrm{~h}$. Gray bar is test bacteria, white bar is negative control and black bar is cell lysate. (B) Dose-dependent leukotoxicity in cultures of THP-1 cells exposed for $2 \mathrm{~h}$ in extract from isolate 12 (grey bars) and the JP2 genotype (black bars) of A. actinomycetemcomitans. Mean \pm SD of triplicate analyses. 


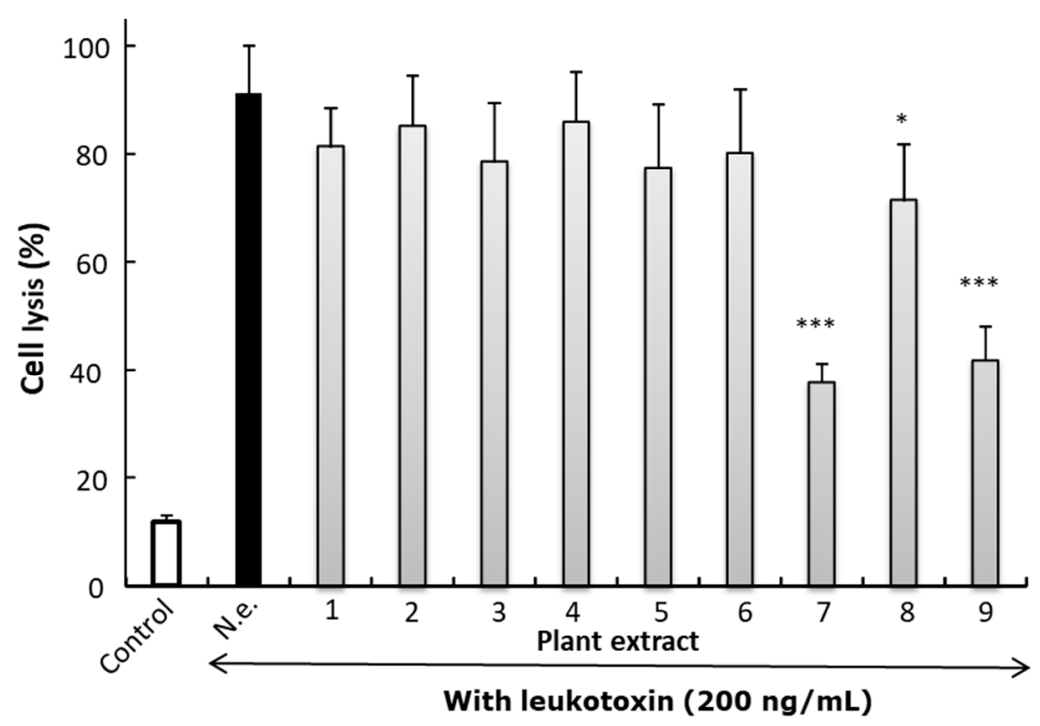

Figure 6. Neutralization of leukotoxicity in the presence of different plant extracts (1\%) on cell lysis in cultures of THP-1 cell exposed for leukotoxin $(200 \mathrm{ng} / \mathrm{mL})$ in 2 h. N.e. No extract, (1) W. ugandensis twigs, (2) W. ugandensis leaves, (3) T. asiatica twigs, (4) T. asiatica leaves, (5) Eucalyptus spp. twigs, (6) G. similis (oirii) twigs, (7) Guava (P. guajava) leaves, (8) fresh extract of W. ugandensis leaves, and (9) fresh extract of W. ugandensis bark. White bar without leukotoxin, black bar with leukotoxin and gray bars leukotoxin + plant extract. Mean \pm SD of four experiments analyzed in triplicates. Student's $t$-test was used to examine significant difference of leukotoxicity without plant extract $\left(p<0.05^{*} . p<0.001^{* * *}\right)$.

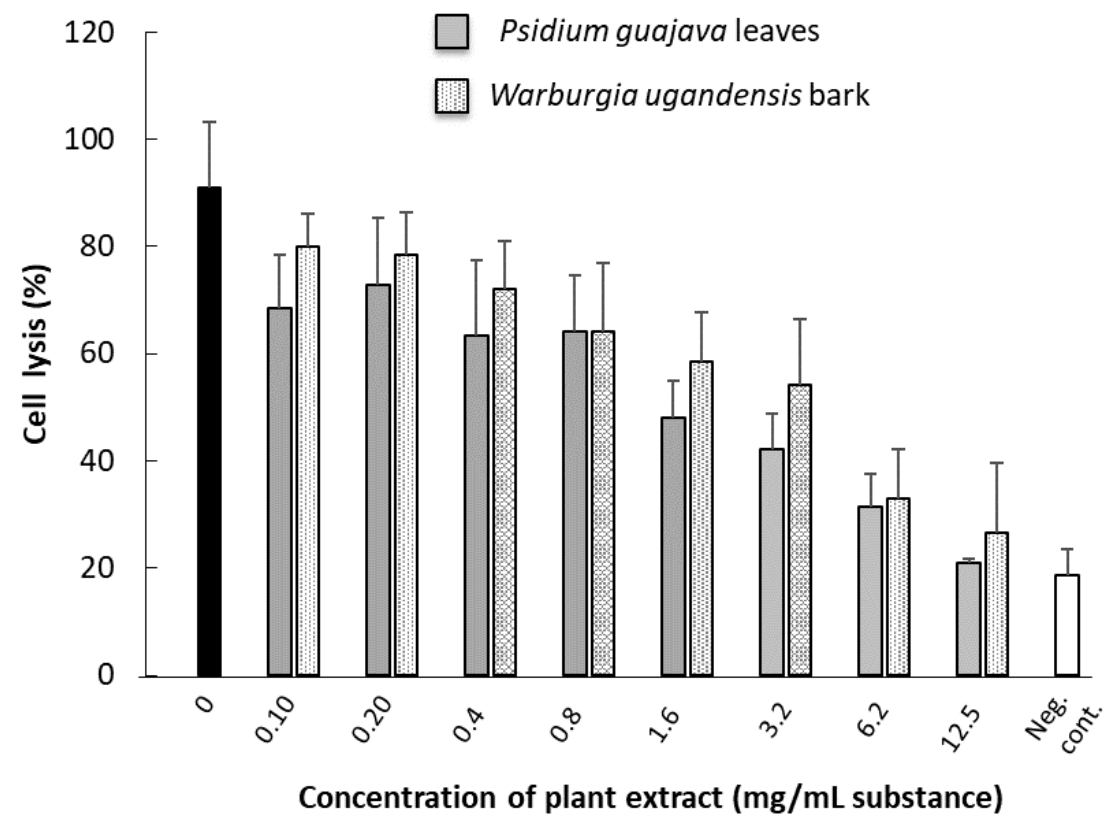

Figure 7. Dose-dependent effect on leukotoxic activity in the presence of extracts from P. guajava leaves or fresh extracts from $W$. ugandensis bark. Black bar with leukotoxin without plant extract. Mean \pm SD of 3-6 observations from two separate experiments. Cultures of THP-1 cells were exposed for leukotoxin $(200 \mathrm{ng} / \mathrm{mL})$ for $2 \mathrm{~h}$. 


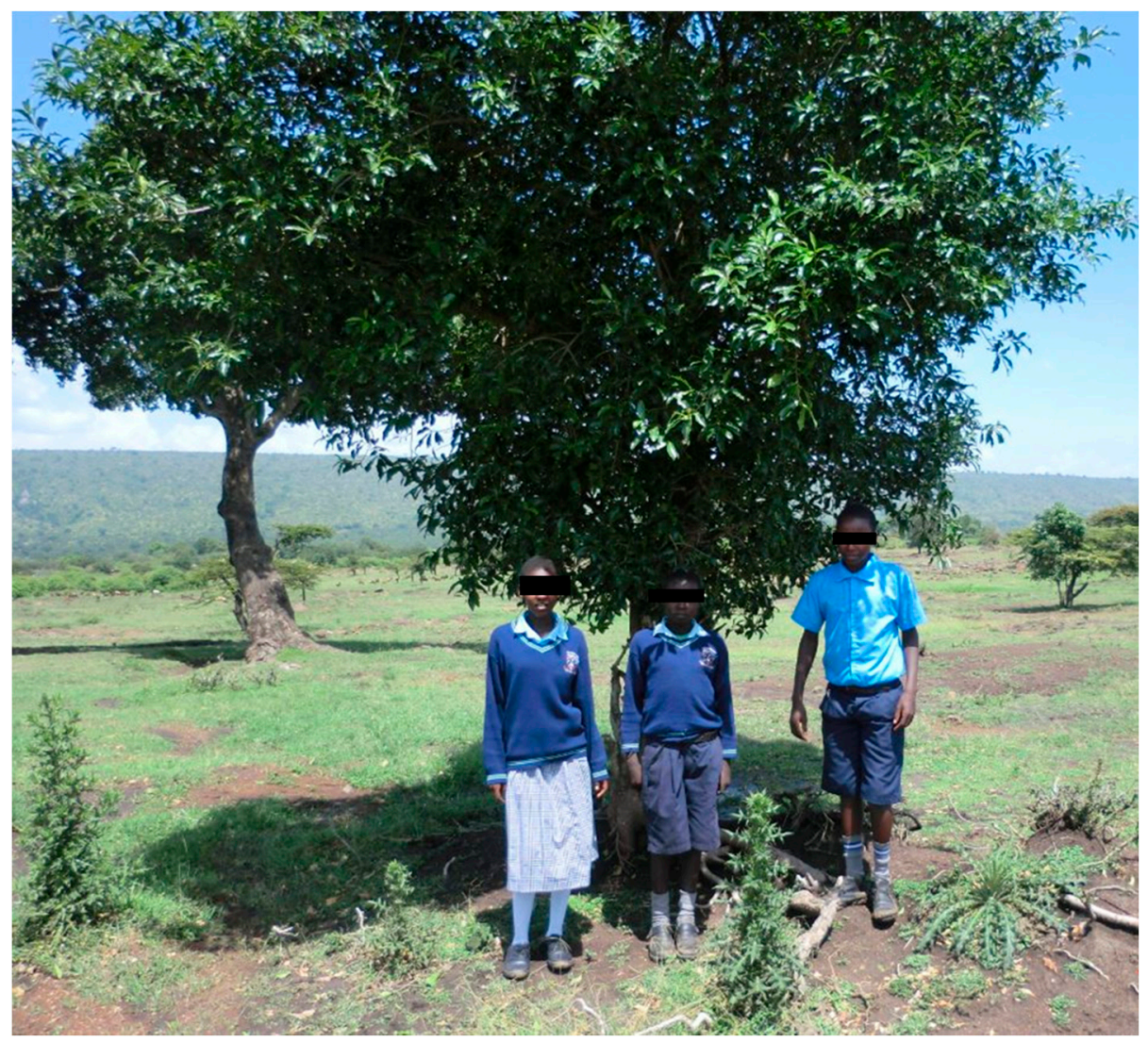

Figure 8. Pupils from the Mara Rianda boarding school standing in front of the W. ugandensis tree that they visit every morning to take a small branch to use as a chewing stick.

\section{Discussion}

In the studied Kenyan Maasai adolescent population $(n=284)$, the salivary presence of A. actinomycetemcomitans was relatively high, with $71.8 \%$ of the population identified as carriers of the bacterium. This determined presence is in parity with other studies from far eastern countries [36-39], and with high carriage rates compared to those of $20-25 \%$ in western countries [40-42]. In a study from Sudan, the presence of A. actinomycetemomitans in subgingival plaque was high $(70.6 \%)$ in cases diagnosed with rapidly progressing periodontitis, while this bacterium was only sporadically detected $(5.9 \%)$ in the healthy controls [43].

Both the presence (99\%) and loads of A. aphrophilus in the present work was found to be high among the examined Maasai adolescents, indicating that this bacterium is a conserved member of the normal oral flora in this population. In comparison with the salivary loads of A. actinomycetemcomitans, the concentrations of A. aphrophilus were substantially higher. Although not much is known regarding the presence of $A$. aphrophilus in populations worldwide, as this species has not been frequently assessed, our observations are consistent with some studies on populations in western Europe [44]. As A. aphrophilus presumably has low virulence potential related to the development of periodontitis, it could be hypothesized that it is beneficial to have high levels of this bacterium, which might allow lower numbers of $A$. actinomycetemcomitans to colonize in the same niche.

Interestingly, the detection of the JP2 genotype of A. actinomycetemcomitans in the present study population confirmed the previously reported observation [12]. By sequencing the leukotoxin promoter operon, we found the characteristic 530-bp deletion originally described by Brogan et al. [7]. A few A. actinomycetemcomitans isolates $(n=12)$ could be cultivated from samples of subgingival plaque; however, none of them were of the JP2 genotype of the bacterium. Further characterization of these isolates showed substantial 
leukotoxic activity in a few of them, but at levels lower than those exhibited by the JP2 genotype of A. actinomycetemcomitans strains.

The dissemination pattern of the JP2 genotype of A. actinomycetemcomitans has been examined in previous studies by analyses of subgingival plaque samples $[5,32,45]$. This strategy requires a stable transport medium, sterile paper points, and instruments to handle the paper points relatively fast, if cultivation is desired [26]. Hence, in the present study, this procedure was performed only with the 58 adolescents sampled on the last day of the field study in order to avoid a too long transportation time of the bacterial samples from the relatively remote research site in Maasai Mara, Kenya, to the laboratory at Umeå University, Umeå, Sweden.

In comparison, saliva, which is easily collected, showed reproducible results over time, and when frozen, it can retain the DNA stable for long periods of time [46,47]. Saliva has also been proven to display comparable results with subgingival plaque samples [48]. This makes saliva more suitable for large population studies, which would also facilitate the possibility of determining the dissemination pattern of the JP2 genotype of $A$. actinomycetemcomitans. Since A. actinomycetemcomitans can be found at different sites in the oral cavity [49], we could also expect to find A. actinomycetemcomitans more frequently, in comparison to when subgingival plaque samples are analyzed.

The plant used for oral hygiene measures by the population of Maasai school pupils, $W$. ugandensis, was found in the area surrounding the schools. As we showed in our experimental setup, the plant extracts had a neutralizing effect on the leukotoxin produced by A. actinomycetemcomitans. This could potentially have an influence on the presence of periodontitis and the virulence capacity of A. actinomycetemcomitans in this area, where this plant is frequently used. We are aware of the limitation of the present study, as the periodontal status was not examined for most of the individuals included. Therefore, no cause-effect relationship could be determined. The potential anti-bacterial effects of the plant towards other oral bacteria are not known but would be relevant to assess, as such effects might contribute to preventing the shift in the oral microbial ecology towards a more periodonto-pathogenic composition.

\section{Conclusions}

In conclusion, we, by the assessment of the adolescent population in Maasai Mara, found the JP2 genotype of A. actinomycetemcomitans, serotype $\mathrm{b}$ for the first time in Kenya. While the reported prevalence of periodontitis in Kenya is low, our finding of a relatively high presence of $A$. actinomycetemcomitans in the examined population could indicate the influence of virulence-modifying factors that may counteract this species. This might include factors such as substances in oral hygiene tools from herbal plants and/or in the commensal oral flora.

Author Contributions: Conceptualization, A.J., D.H. and A.K.; methodology, D.H., A.J., R.C., J.O. and M.L.; validation, J.O., A.J. and M.L.; formal analysis, R.C., M.L.; investigation, D.H., M.L., T.M., A.K. and A.J.; resources, D.H. and A.J.; data curation, J.O., M.L. and A.J.; writing-original draft preparation, A.J. and M.L.; writing-review and editing, D.H., J.O., R.C. and T.M.; visualization, A.J., M.L. and R.C.; supervision, J.O. and A.J.; project administration, D.H. and A.K.; funding acquisition, D.H., A.J. and J.O. All authors have read and agreed to the published version of the manuscript.

Funding: This research was funded by TUA grants from the County Council of Västerbotten, Sweden (A.J.; 7003193 and J.O.; 7002667) the Swedish Dental Society and the Kempe Foundation (M.L.) and from Ingeborg and Leo Dannin's Foundation, Denmark (D.H.).

Institutional Review Board Statement: The study was conducted according to the guidelines of the Declaration of Helsinki and approved by the KNH-UoN Ethics and Research Committee, Kenya (P711/11/2015, 25 January 2016).

Informed Consent Statement: The parent/guardian and child also provided written informed consent and assent, respectively, after full disclosure of the study had been given to them. Permission 
to carry out the research at schools in the Mara North Conservancy was sought from the relevant authorities in Kenya.

Data Availability Statement: Microbiological data are stored by AJ at the University of Umeå, Sweden.

Acknowledgments: We are grateful to the staff at Karen Blixen Camp for supporting our activities while we conducted our field studies in Maasai Mara, Kenya. Our thanks also go to the board of the MMSDI project at Aarhus University, and Joseph Nabala of Maasai Mara for giving advice and various types of information needed to make this project possible. Our thanks go to the teacher of biology, Lefura Benjamin Nkaate, at Maasai Mara High School, for valuable information about the medicine plants and to all the teenagers and their guardians who contributed to and made this study possible. We are grateful for the practical assistance from Hans Gjørup and Marie-Louise Milvang Nørregaard in the collection of a limited number of subgingival plaque samples. Finally, we are grateful to Francis Kwamin at the University of Ghana in Accra, who kindly collected Psidium guajava leaves.

Conflicts of Interest: The authors declare no conflict of interest.

\section{References}

1. Henderson, B.; Ward, J.M.; Ready, D. Aggregatibacter (Actinobacillus) actinomycetemcomitans: A triple A* periodontopathogen? Periodontol. 2000 2010, 54, 78-105. [CrossRef]

2. Nedergaard, S.; Kobel, C.M.; Nielsen, M.B.; Moller, R.T.; Jensen, A.B.; Norskov-Lauritsen, N. Whole genome sequencing of Aggregatibacter actinomycetemcomitans Cultured from blood stream infections reveals three major phylogenetic groups including a Novel lineage expressing serotype a membrane O polysaccharide. Pathogens 2019, 8, 256. [CrossRef] [PubMed]

3. Nørskov-Lauritsen, N. Classification, identification, and clinical significance of Haemophilus and Aggregatibacter species with host specificity for humans. Clin. Microbiol. Rev. 2014, 27, 214-240. [CrossRef]

4. Konig, M.F.; Abusleme, L.; Reinholdt, J.; Palmer, R.J.; Teles, R.P.; Sampson, K.; Rosen, A.; Nigrovic, P.A.; Sokolove, J.; Giles, J.T.; et al. Aggregatibacter actinomycetemcomitans-induced hypercitrullination links periodontal infection to autoimmunity in rheumatoid arthritis. Sci. Transl. Med. 2016, 8, 369ra176. [CrossRef] [PubMed]

5. Haubek, D.; Ennibi, O.K.; Poulsen, K.; Vaeth, M.; Poulsen, S.; Kilian, M. Risk of aggressive periodontitis in adolescent carriers of the JP2 clone of Aggregatibacter (Actinobacillus) actinomycetemcomitans in Morocco: A prospective longitudinal cohort study. Lancet 2008, 371, 237-242. [CrossRef]

6. Höglund Åberg, C.; Kwamin, F.; Claesson, R.; Dahlen, G.; Johansson, A.; Haubek, D. Progression of attachment loss is strongly associated with presence of the JP2 genotype of Aggregatibacter actinomycetemcomitans: A prospective cohort study of a young adolescent population. J. Clin. Periodontol. 2014, 41, 232-241. [CrossRef]

7. Brogan, J.M.; Lally, E.T.; Poulsen, K.; Kilian, M.; Demuth, D.R. Regulation of Actinobacillus actinomycetemcomitans leukotoxin expression: Analysis of the promoter regions of leukotoxic and minimally leukotoxic strains. Infect. Immun. 1994, 62, 501-508. [CrossRef] [PubMed]

8. Johansson, A.; Claesson, R.; Hänstrom, L.; Sandström, G.; Kalfas, S. Polymorphonuclear leukocyte degranulation induced by leukotoxin from Actinobacillus actinomycetemcomitans. J. Periodontal Res. 2000, 35, 85-92. [CrossRef] [PubMed]

9. Johansson, A.; Hanstrom, L.; Kalfas, S. Inhibition of Actinobacillus actinomycetemcomitans leukotoxicity by bacteria from the subgingival flora. Oral Microbiol. Immunol. 2000, 15, 218-225. [CrossRef]

10. Kelk, P.; Claesson, R.; Chen, C.; Sjöstedt, A.; Johansson, A. IL-1beta secretion induced by Aggregatibacter (Actinobacillus) actinomycetemcomitans is mainly caused by the leukotoxin. Int. J. Med Microbiol. IJMM 2008, 298, 529-541. [CrossRef] [PubMed]

11. Åberg, C.H.; Kelk, P.; Johansson, A. Aggregatibacter actinomycetemcomitans: Virulence of its leukotoxin and association with aggressive periodontitis. Virulence 2015, 6, 188-195. [CrossRef] [PubMed]

12. Haubek, D.; Mulli, T.; Kemoli, A.; Lindholm, M.; Gjørup, H.; Nørregaard, M.M.; Johansson, A. Prevalence of JP2 and non-JP2 genotypes of Aggregatibacter actinomycetemcomitans and oral hygiene practice of Kenyan adolescents in Maasai Mara. Pathogens 2021, 10, 488. [CrossRef] [PubMed]

13. Elamin, A.M.; Skaug, N.; Ali, R.W.; Bakken, V.; Albandar, J.M. Ethnic disparities in the prevalence of periodontitis among high school students in Sudan. J. Periodontol. 2010, 81, 891-896. [CrossRef]

14. Elamin, A.; Albandar, J.M.; Poulsen, K.; Ali, R.W.; Bakken, V. Prevalence of Aggregatibacter actinomycetemcomitans in Sudanese patients with aggressive periodontitis: A case-control study. J. Periodontal Res. 2011, 46, 285-291. [CrossRef] [PubMed]

15. Elabdeen, H.R.; Mustafa, M.; Hasturk, H.; Klepac-Ceraj, V.; Ali, R.W.; Paster, B.J.; Van Dyke, T.; Bolstad, A.I. Subgingival microbial profiles of Sudanese patients with aggressive periodontitis. J. Periodontal Res. 2015, 50, 674-682. [CrossRef]

16. Claesson, R.; Gudmundson, J.; Åberg, C.H.; Haubek, D.; Johansson, A. Detection of a 640-bp deletion in the Aggregatibacter actinomycetemcomitans leukotoxin promoter region in isolates from an adolescent of Ethiopian origin. J. Oral Microbiol. 2015, 7, 26974. [CrossRef] [PubMed]

17. Wagaiyu, E.G.; Wagaiyu, C.K. Prevalence of juvenile periodontitis in national youth service trainees. East Afr. Med. J. 1992, 69, 31-33. 
18. Kemoli, A.; Gjørup, H.; Nørregaard, M.M.; Lindholm, M.; Mulli, T.; Johansson, A.; Haubek, D. Prevalence and impact of infant oral mutilation on dental occlusion and oral health-related quality of life among Kenyan adolescents from Maasai Mara. BMC Oral Health 2018, 18, 173. [CrossRef]

19. Nørskov-Lauritsen, N.; Claesson, R.; Birkeholm Jensen, A.; Aberg, C.H.; Haubek, D. Aggregatibacter Actinomycetemcomitans: Clinical significance of a pathobiont subjected to ample changes in classification and nomenclature. Pathogens $2019,8,243$. [CrossRef] [PubMed]

20. Ennibi, O.K.; Claesson, R.; Akkaoui, S.; Reddahi, S.; Kwamin, F.; Haubek, D.; Johansson, A. High salivary levels of JP2 genotype of Aggregatibacter actinomycetemcomitans is associated with clinical attachment loss in Moroccan adolescents. Clin. Exp. Dent. Res. 2019, 5, 44-51. [CrossRef]

21. Kemoli, A.M.; van Amerongen, W.E.; de Soet, J.J. Antimicrobial and buffer capacity of crude extracts of chewing sticks (Miswaki) from Kenya. ASDC J. Dent. Child. 2001, 68, 183-188, 152.

22. Kwamin, F.; Gref, R.; Haubek, D.; Johansson, A. Interactions of extracts from selected chewing stick sources with Aggregatibacter actinomycetemcomitans. BMC Res. Notes 2012, 5, 203. [CrossRef] [PubMed]

23. Nankaya, J.; Gichuki, N.; Lukhoba, C.; Balslev, H. Medicinal plants of the Maasai of Kenya: A Review. Plants 2019, 9, 44. [CrossRef] [PubMed]

24. Bussmann, R.W.; Gilbreath, G.G.; Solio, J.; Lutura, M.; Lutuluo, R.; Kunguru, K.; Wood, N.; Mathenge, S.G. Plant use of the Maasai of Sekenani Valley, Maasai Mara, Kenya. J. Ethnobiol. Ethnomed. 2006, 2, 22. [CrossRef] [PubMed]

25. Kittichotirat, W.; Bumgarner, R.E.; Chen, C. Evolutionary divergence of Aggregatibacter actinomycetemcomitans. J. Dent. Res. 2016, 95, 94-101. [CrossRef]

26. Dahlen, G.; Pipattanagovit, P.; Rosling, B.; Moller, A.J. A comparison of two transport media for saliva and subgingival samples. Oral Microbiol. Immunol. 1993, 8, 375-382. [CrossRef]

27. Kirakodu, S.S.; Govindaswami, M.; Novak, M.J.; Ebersole, J.L.; Novak, K.F. Optimizing qPCR for the Quantification of periodontal pathogens in a complex plaque biofilm. Open Dent. J. 2008, 2, 49-55. [CrossRef]

28. Di Bonaventura, M.P.; DeSalle, R.; Pop, M.; Nagarajan, N.; Figurski, D.H.; Fine, D.H.; Kaplan, J.B.; Planet, P.J. Complete genome sequence of Aggregatibacter (Haemophilus) aphrophilus NJ8700. J. Bacteriol. 2009, 191, 4693-4694. [CrossRef]

29. Suzuki, N.; Nakano, Y.; Yoshida, Y.; Ikeda, D.; Koga, T. Identification of Actinobacillus actinomycetemcomitans serotypes by multiplex PCR. J. Clin. Microbiol. 2001, 39, 2002-2005. [CrossRef]

30. Poulsen, K.; Ennibi, O.K.; Haubek, D. Improved PCR for detection of the highly leukotoxic JP2 clone of Actinobacillus actinomycetemcomitans in subgingival plaque samples. J. Clin. Microbiol. 2003, 41, 4829-4832. [CrossRef] [PubMed]

31. Slots, J. Selective medium for isolation of Actinobacillus actinomycetemcomitans. J. Clin. Microbiol. 1982, 15, 606-609. [CrossRef]

32. Aberg, C.H.; Kwamin, F.; Claesson, R.; Johansson, A.; Haubek, D. Presence of JP2 and non-JP2 genotypes of Aggregatibacter actinomycetemcomitans and attachment loss in adolescents in Ghana. J. Periodontol. 2012, 83, 1520-1528. [CrossRef]

33. Haubek, D.; Havemose-Poulsen, A.; Westergaard, J. Aggressive periodontitis in a 16-year-old Ghanaian adolescent, the original source of Actinobacillus actinomycetemcomitans strain HK1651-A 10-year follow up. Int. J. Paediatr. Dent. 2006, 16, 370-375. [CrossRef]

34. Lindholm, M.; Min Aung, K.; Nyunt Wai, S.; Oscarsson, J. Role of OmpA1 and OmpA2 in Aggregatibacter actinomycetemcomitans and Aggregatibacter aphrophilus serum resistance. J. Oral Microbiol. 2019, 11, 1536192. [CrossRef]

35. Höglund Åberg, C.; Haubek, D.; Kwamin, F.; Johansson, A.; Claesson, R. Leukotoxic activity of Aggregatibacter actinomycetemcomitans and periodontal attachment loss. PLoS ONE 2014, 9, e104095. [CrossRef]

36. Timmerman, M.F.; Van der Weijden, G.A.; Armand, S.; Abbas, F.; Winkel, E.G.; Van Winkelhoff, A.J.; Van der Velden, U. Untreated periodontal disease in Indonesian adolescents. Clinical and microbiological baseline data. J. Clin. Periodontol. 1998, 25, 215-224. [CrossRef]

37. Mombelli, A.; Gmür, R.; Frey, J.; Meyer, J.; Zee, K.Y.; Tam, J.O.; Lo, E.C.; Di Rienzo, J.; Lang, N.P.; Corbet, E.F. Actinobacillus actinomycetemcomitans and Porphyromonas gingivalis in young Chinese adults. Oral Microbiol. Immunol. 1998, 13, $231-237$. [CrossRef] [PubMed]

38. Mombelli, A.; Gmur, R.; Lang, N.P.; Corbert, E.; Frey, J. Actinobacillus actinomycetemcomitans in Chinese adults. Serotype distribution and analysis of the leukotoxin gene promoter locus. J. Clin. Periodontol. 1999, 26, 505-510. [CrossRef]

39. Dahlen, G.; Widar, F.; Teanpaisan, R.; Papapanou, P.N.; Baelum, V.; Fejerskov, O. Actinobacillus actinomycetemcomitans in a rural adult population in southern Thailand. Oral Microbiol. Immunol. 2002, 17, 137-142. [CrossRef] [PubMed]

40. Könönen, E.; Paju, S.; Pussinen, P.J.; Hyvonen, M.; Di Tella, P.; Suominen-Taipale, L.; Knuuttila, M. Population-based study of salivary carriage of periodontal pathogens in adults. J. Clin. Microbiol. 2007, 45, 2446-2451. [CrossRef] [PubMed]

41. Papapanou, P.N.; Sellen, A.; Wennström, J.L.; Dahlen, G. An analysis of the subgingival microflora in randomly selected subjects. Oral Microbiol. Immunol. 1993, 8, 24-29. [CrossRef]

42. Hamlet, S.M.; Cullinan, M.P.; Westerman, B.; Lindeman, M.; Bird, P.S.; Palmer, J.; Seymour, G.J. Distribution of Actinobacillus actinomycetemcomitans, Porphyromonas gingivalis and Prevotella intermedia in an Australian population. J. Clin. Periodontol. 2001, 28, 1163-1171. [CrossRef]

43. Elamin, A.; Ali, R.W.; Bakken, V. Putative periodontopathic bacteria and herpes viruses interactions in the subgingival plaque of patients with aggressive periodontitis and healthy controls. Clin. Exp. Dent. Res. 2017, 3, 183-190. [CrossRef] 
44. Tempro, P.J.; Slots, J. Selective medium for the isolation of Haemophilus aphrophilus from the human periodontium and other oral sites and the low proportion of the organism in the oral flora. J. Clin. Microbiol. 1986, 23, 777-782. [CrossRef]

45. Contreras, A.; Rusitanonta, T.; Chen, C.; Wagner, W.G.; Michalowicz, B.S.; Slots, J. Frequency of 530-bp deletion in Actinobacillus actinomycetemcomitans leukotoxin promoter region. Oral Microbiol. Immunol. 2000, 15, 338-340. [CrossRef]

46. Belstrøm, D.; Holmstrup, P.; Bardow, A.; Kokaras, A.; Fiehn, N.-E.; Paster, B.J. Temporal stability of the salivary microbiota in oral health. PLOS ONE 2016, 11, e0147472. [CrossRef] [PubMed]

47. Janardhanam, S.B.; Zunt, S.L.; Srinivasan, M. Quality assessment of saliva bank samples. Biopreserv. Biobank. 2012, 10, $282-287$. [CrossRef] [PubMed]

48. Belstrøm, D.; Holmstrup, P.; Bardow, A.; Kokaras, A.; Fiehn, N.-E.; Paster, B.J. Comparative analysis of bacterial profiles in unstimulated and stimulated saliva samples. J. Oral Microbiol. 2016, 8, 30112. [CrossRef] [PubMed]

49. Müller, H.P.; Heinecke, A.; Fuhrmann, A.; Eger, T.; Zöller, L. Intraoral distribution of Actinobacillus actinomycetemcomitans in young adults with minimal periodontal disease. J. Periodontal Res. 2001, 36, 114-123. [CrossRef] 